\title{
Study of Air Flow Interaction with Pilot Injections in a Diesel Engine by Means of PIV Measurements
}

\author{
Jose M Garcia-Oliver, Antonio Garcia, Antonio Gil, and Leonardo Pachano \\ Universitat Politecnica de Valencia
}

\begin{abstract}
With ever-demanding emission legislations in Compression Ignition (CI) engines, new premixed combustion strategies have been developed in recent years seeking both, emissions and performance improvements. Since it has been shown that in-cylinder air flow affects the combustion process, and hence the overall engine performance, the study of swirling structures and its interaction with fuel injection are of great interest. In this regard, possible Turbulent Kinetic Energy (TKE) distribution changes after fuel injection may be a key parameter for achieving performance improvements by reducing in-cylinder heat transfer. Consequently, this paper aims to gain an insight into spray-swirl interaction through the analysis of in-cylinder velocity fields measured by Particle Image Velocimetry (PIV) when PCCI conditions are proposed. Experiments are carried out in a single cylinder optical Diesel engine with bowl-in-piston geometry. A standard 2D PIV system is used for measuring instantaneous velocity fields in a cross section (swirl-plane) inside the combustion chamber. The test matrix is based on an advanced single pilot injection with energizing time and injection pressure sweeps at different crank-angles. Results show that swirl ratio decreases with the increase of injected fuel mass. The decrease in swirl ratio also comes with a homogenization of the flow field. This homogenization along with lower swirl ratios might decrease heat transfer to cylinder walls.
\end{abstract}

CITATION: Garcia-Oliver, J., Garcia, A., Gil, A., and Pachano, L., "Study of Air Flow Interaction with Pilot Injections in a Diesel Engine by Means of PIV Measurements," SAE Int. J. Engines 10(3):2017, doi:10.4271/2017-01-0617.

\section{INTRODUCTION}

During the last years the development of new combustion concepts leading towards higher fuel efficiency levels and lower pollutant emissions have been an active research topic in the engine sector. Even though CI engines are known for their high fuel efficiency compared to Spark Ignition engines, levels of NOx and PM emissions are still a major concern. With the introduction of stricter emissions legislation, reducing exhaust emissions is becoming a more challenging task. As a result, new combustion concepts such as PCCI have been drawing attention. PCCI combustion can be achieved by advancing the injection event. If the injection event is well advanced ignition delay can be long enough so start of combustion takes place after the end of injection. This early injection strategy combined with EGR allows to decouple injection and combustion events providing an extra mixing time after the end of injection and consequently promoting a premixed low temperature combustion that achieves a simultaneous reduction of NOx and PM emissions $[\underline{1}, \underline{2}, \underline{3}, \underline{4}]$. Thus, it is possible to state that mixing process will not only be governed by injection process but also for the in-cylinder flow structures. In this sense, the study of the interaction between an advanced pilot injection and in-cylinder flow structures is of great interest. In light-duty (LD) CI engines with bowl-in-piston geometries the study of spray-swirl interaction is of particular importance since swirl is the flow structure behind large-scale transportation of air [ $\underline{5}]$. The analysis of swirl interaction with fuel injection may lead to a better understanding of in-cylinder processes such as fuel-air mixture and wall heat transfer under PCCI conditions.
As a part of this analysis, laser-based optical techniques can be used to measure in-cylinder velocities []․ On this subject, Zha et al. [ㅁ] characterized swirl center motion during compression stroke in a LD Diesel engine with a realistic piston geometry using PIV. Results from this study shows that the swirl structure develops asymmetrically leading to an asymmetry mixture preparation. Regarding studies with fuel injection, Zegers et al. [7] used high speed PIV to study flow pattern changes during and after fuel injection in a heavy-duty optical Diesel engine. Velocity maps show that there is a sudden change in flow structure at the beginning of the injection event due to air entrainment into the fuel spray core.

Findings in that same direction were made by Valentino et al. [ $\underline{8}]$. The authors used PIV to evaluate spray structure for different nozzles and injection strategies. From their results it was shown that air entrainment induce changes in the flow structure. This work also evaluated the effect of different nozzles and injection strategies on NOx and HC emissions. Another optical measurement technique derived from PIV known as Combustion Image Velocimetry (CIV) has been used to analyze the influence of fuel injection parameters on flow structure during the after-oxidation period $[\underline{9}, \underline{10}]$. Flow structure changes induced by swirl ratio and injection pressure variations seem to have a deep impact on pollutants formation.

As it has been reported, changes in flow structure can affect exhaust emissions. Based on that, improving the understanding of the in-cylinder flow pattern has been the motivation for several research works. Thus, more recently, Tanov et al. [11] analyzed changes in 
turbulence levels associated with different fuel injection strategies by means of cycle-resolved high speed PIV. Measurements were carried out in a vertical plane in an optical Diesel engine. It was shown that changes in turbulence evolution during compression stroke are highly dependent on the number of injection events. Indeed, combustion is shown as minor contributor to the changes in turbulence and air flow motion compared with the fuel injection impact.

Thus, considering the main impact of injection processes on air flow motion demonstrated in the literature, the objective of this work is to gain an insight into spray-swirl interaction through the analysis of in-cylinder velocity fields measured by PIV under non-reacting conditions using a PCCI injection strategy in a light-duty Diesel engine. Testing under non-reacting conditions offers several advantages such as reduced window fouling with no PM. In reference to injection events, momentum flux was varied by changing injection pressure and fuel injected mass by varying Energizing Time (ET). To experimentally characterize the in-cylinder flow, 2D velocity maps were measured in a horizontal cross-section over the piston top for two crank-angles before firing TDC. Injection strategy was based on a single advanced pilot injection. All PIV measurements were carried out 3 Crank-angle Degrees (CAD) after the End of Injection (aEoI). ET and injection pressure influence on velocity and TKE fields were analyzed. From those results, effect of fuel injection on swirl ratio and heat transfer coefficient has been evaluated.

\section{EXPERIMENTAL APPARATUS AND PROCESSING TOOLS}

\section{Test Cell}

This section describes the experimental configuration of the test cell and the main subsystems used in this study. As Figure 1 shows, the single cylinder engine is installed in a fully instrumented test cell, with all the auxiliary facilities required for operation and control.

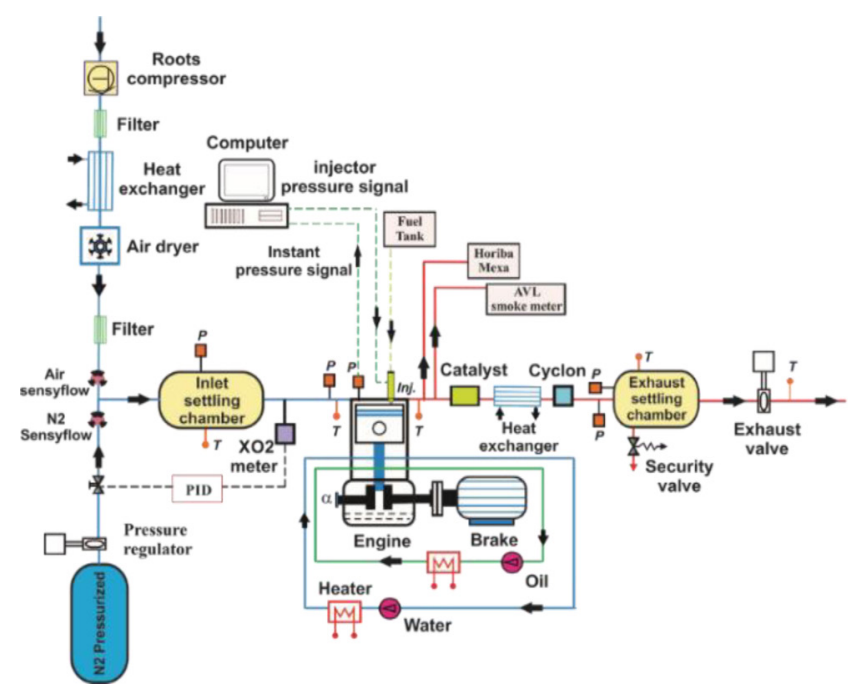

Figure 1. Complete test cell set-up.

The intake air is supplied by a roots compressor with an upper pressure limit of 3 bar. Then, the air flows through a filter to remove possible impurities. Independently on the ambient conditions, temperature and humidity of intake air are controlled using a heat exchanger and a dryer. Temperature in the inlet settling chamber is maintained constant by using a heater in the intake line.

Oxygen concentration variation is performed introducing N2 into the inlet flow. This approach greatly simplifies the system ensuring a controllable gas composition without an excessive time to adjust the facility. The strategy is based on decreasing the $\mathrm{O} 2$ concentration at the inlet manifold by increasing the flow of N2 and keeping the total intake mass flow rate constant. For this purpose a PID controller is equipped to operate an $\mathrm{N} 2$ valve governed by the intake $\mathrm{O} 2$ meter. In that sense, all tests are conducted with just N2 as intake charge ensuring non-reacting conditions.

In the exhaust line, after the exhaust analyzer sample probe, a cyclone is needed to remove the hydrocarbons. In the same way as in the intake line, a settling chamber is mounted in order to attenuate pressure pulses. Finally, an exhaust backpressure valve is used to maintain a fixed relative pressure to the intake pressure, in order to simulate more realistic conditions.

\section{Single-Cylinder Optical LD Diesel Engine}

The study was carried out on a single cylinder optical Direct Injection (DI) Diesel engine. It is derived from a commercial PSA 2.2 L Diesel engine equipped with a Common-Rail fuel injection system. It has four valves per cylinder and a centrally located injector. Swirl flaps allows for swirl ratio variation. The engine is equipped with a Bowditch [12] elongated notched piston with a cylindrical bowl which allows optical access to the combustion chamber through a sapphire window placed at the bottom of the bowl. In addition, quartz windows on the partially extended liner and in the piston upper part allow optical access into the bowl from the side. In addition, a partially extended quartz liner in the upper cylinder part together with the piston side windows allows optical access into the piston bowl from the side. Figure 2 shows a schematic figure of the engine.

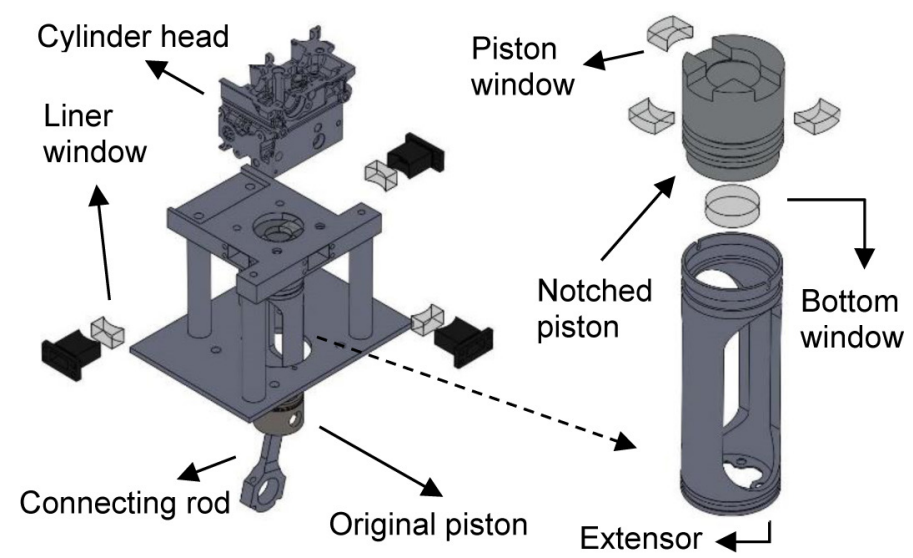

Figure 2. Optical engine.

The fuel injection system is based on an electronically controlled Bosch common rail system. The injector is a Bosch solenoid equipped with a five-hole nozzle. The nozzle orifice diameter is 187 microns. The injection control system makes it possible to modify any injection 
event parameter such as the Start of Injection (SoI) timing, injection duration and rail pressure. Both, engine and fuel injection hardware characteristics are summarized in Table 1 and Table 2.

Table 1. Engine system main characteristics.

\begin{tabular}{|c|c|}
\hline \multicolumn{2}{|c|}{ Engine } \\
\hline Type & CI, 4 stroke, DI \\
\hline Bore [mm] & 85 \\
\hline Stroke [mm] & 96 \\
\hline Squish height [mm] & 1.5 \\
\hline Compression ratio & $15.2: 1$ \\
\hline Bowl diameter [mm] & 45 \\
\hline Bowl depth [mm] & 12 \\
\hline Inlet valve closing [CAD] & 565 \\
\hline Exhaust valve opening [CAD] & 162 \\
\hline
\end{tabular}

Table 2. Injection system main characteristics.

\begin{tabular}{|c|c|}
\hline \multicolumn{2}{|c|}{ Injection system } \\
\hline Actuation Type & Solenoid \\
\hline Included angle & 144 \\
\hline Nozzle & Cylindrical with 5 orifices \\
\hline Orifice diameter $[\mu \mathrm{m}]$ & 187 \\
\hline
\end{tabular}

As for the fuel injected, commercially available European Diesel fuel was used for this work. Fuel density and dynamic viscosity at $1 \mathrm{~atm}$ and $313 \mathrm{~K}$ are $820 \mathrm{~kg} / \mathrm{m}^{3}$ and $2.38 \mathrm{cStk}$, respectively.

\section{Theoretical Tools}

\section{D Thermodynamic Models (CALMEC - SiCiclo)}

Two different 0D single-zone thermodynamic models (CALMEC and siCiclo) were used to characterize the engine. Main assumptions for both thermodynamic models are:

- The chamber is considered an open system to account for the fuel injection and blow-by leakage.

- Combustion chamber pressure and temperature are assumed to be spatially uniform.

- Three species (air, fuel vapor and stoichiometric combustion products) are considered [14]

- Ideal gas law is used to calculate gas temperature.

- A filling and emptying model is used to calculate the trapped mass [15].

- The specific heat of the gas depends on both temperature and composition [16].

- Blow-by model is based on the evolution of the gas in an isentropic nozzle [15] .
- The chamber volume deformation due to pressure and inertia is calculated by means of a simple deformation model [17].

- The heat transfer coefficient in the chamber walls is calculated with a modified Woschni-like model (1) [18]:

$$
h=C D^{-0.2} p^{0.8} T^{-053}\left[C_{W 1} C_{m}+C_{W 2} C_{u}\right]^{0.8}
$$

Where $\mathrm{C}$ and $\mathrm{C}_{2}$ are constants whose values are 0.012 and 0.001 , D is the cylinder diameter, $\mathrm{p}$ and $\mathrm{T}$ are the instant pressure and gas temperature, $\mathrm{V}_{\mathrm{d}}$ is the swept volume, $\mathrm{c}_{\mathrm{m}}$ is the mean piston speed, $\mathrm{c}_{\mathrm{u}}$ is the instantaneous tangential velocity of the gas in the chamber adjusted using CFD calculations [18], and $\mathrm{C}_{\mathrm{W} 1}$ and $\mathrm{C}_{\mathrm{W} 2}$ are constants, whose values are adjusted for each engine by means of a combination of experimental and modeling methodology.

SiCiclo [14] is a predictive tool that provides the in- cylinder pressure evolution. This code was used to model pressure and volume inside the cylinder. On the other hand, CALMEC is a thermodynamic diagnosis tool. It is used to calculate the instantaneous evolution of in-cylinder properties of the gas and to model the internal energy terms [13]. This diagnosis tool uses the in-cylinder pressure as its main input. The in-cylinder pressure was measured with a Kistler 6055B80 pressure transducer. A shaft encoder with 1800 pulses per revolution was used, which allows a $0.2 \mathrm{CAD}$ resolution. Pressure traces for 50 engine cycles were recorded in order to compensate the cycle-to-cycle variations during engine operation. Thus, each individual cycle's pressure data was smoothed using a Fourier series low-pass filter. Once filtered, the collected cycles were ensemble averaged to yield a representative cylinder pressure trace, which was used to perform the analysis.

As previously stated, these $0 \mathrm{D}$ tools use a simple model to estimate mechanical deformations. Nonetheless, major mechanical deformations (compared to regular engine configurations) have been reported for Bowditch type optical engines [19]. To evaluate changes due to mechanical deformations a structural analysis was performed using the Finite Element Method (FEM). The analysis was mainly focused on the piston extensor since considerable axial deformation is expected. The simulation was carried out in ANSYS workbench and the results for the axial deformation at TDC are shown Figure 3. Four different meshes with consecutive refinements around the zone with higher deformations were tested to evaluate mesh independence. It was found that a maximum $1.6 \mathrm{~mm}$ axial deformation is reached under the critical conditions met at TDC. To account for this behavior the deformation model used by the $0 \mathrm{D}$ thermodynamic models was adjusted to simulate mechanical deformation based on the FEM analysis results.

Increase in squish height mainly affects in-cylinder volume around TDC. Figure 4 shows the in-cylinder volume evolution around this crank-angle estimated using SiCiclo. It can be seen that volume at TDC is higher for the case considering mechanical deformations. This bigger volume means a bigger amount of air is kept outside the bowl not contributing to airflow acceleration. This behavior should lead to a lower swirl ratio level around TDC compared to an engine 
with similar characteristics without the elongated Bowditch piston. Additionally, in-cylinder volume variations at TDC are relevant for a more accurate estimation of compression ratio.

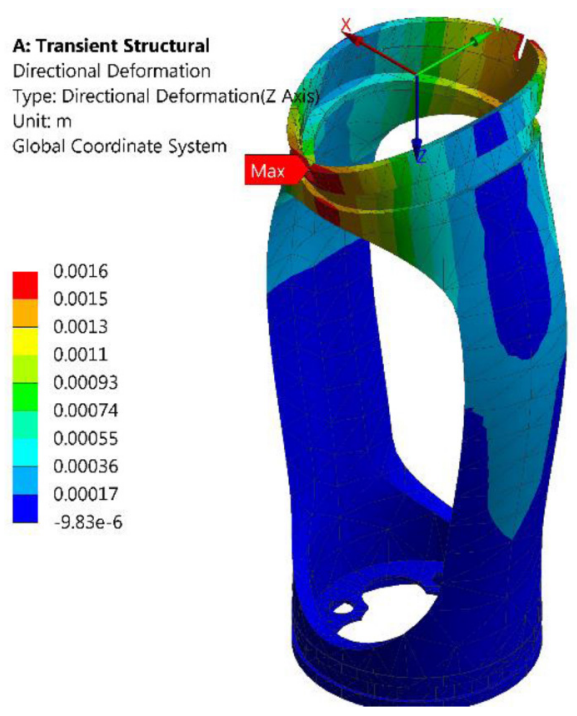

Figure 3. FEM results for extensor axial deformation.

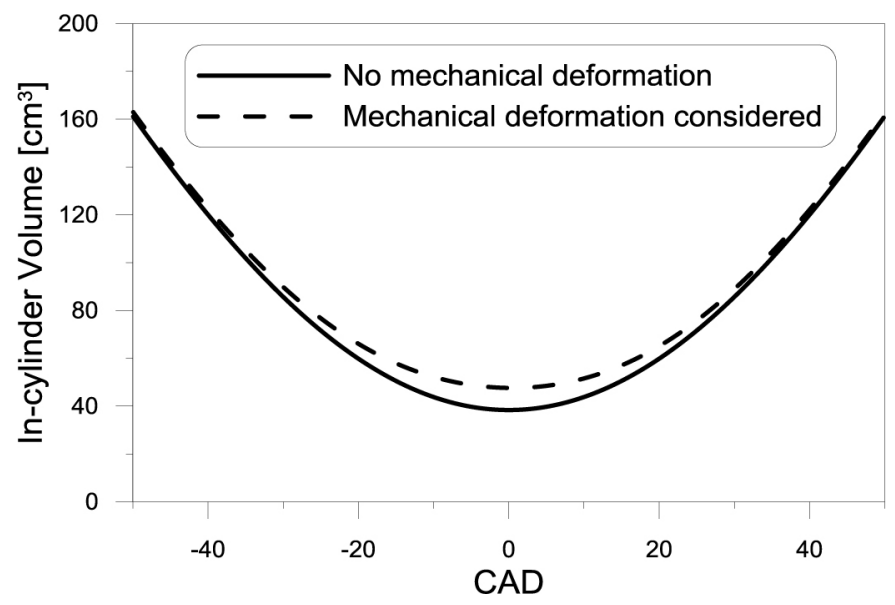

Figure 4. Mechanical deformation impact on in-cylinder volume.

Once the mechanical deformation model has been adjusted to account for larger mechanical deformations, in-cylinder pressure was modeled with SiCiclo and compared to the experimental measurement. Figure $\underline{5}$ shows that SiCiclo is able to model the in-cylinder pressure with a good level of agreement. Pressure at IVC (155 bTDC) and peak pressure are well captured by the model. Some differences are found at EVO (162 aTDC), but within a reasonable range.

Finally, Table 3 summarizes engine characterization results from CALMEC. Effective compression ratio is found to be lower than the geometric compression ratio. This difference is expected due to the in-cylinder volume variation at TDC associated with the increase in squish height. Regarding heat transfer, coefficients for the Woschnilike model are within the typical range for light-duty Diesel engine.

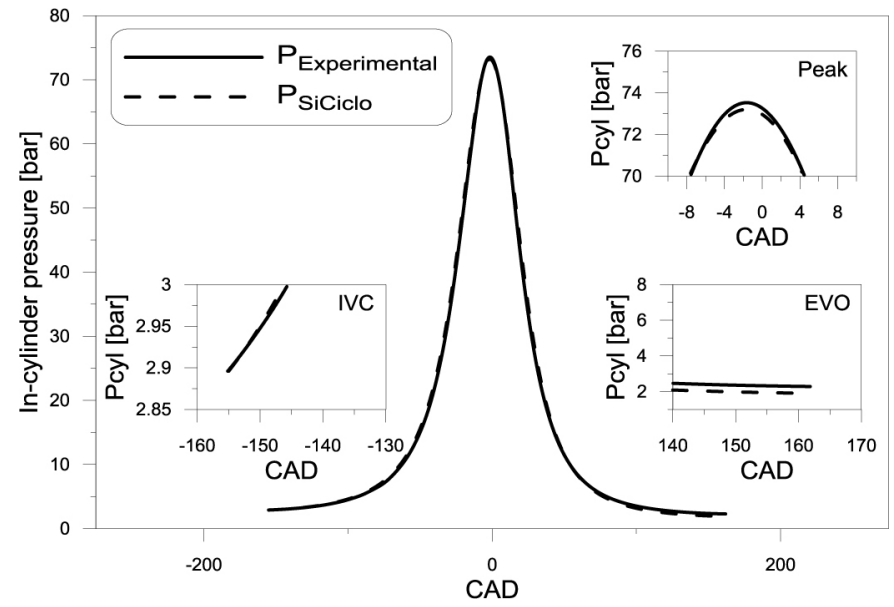

Figure 5. In-cylinder pressure modeled with SiCiclo vs experimental measurement.

Table 3. Engine characterization results from CALMEC.

\begin{tabular}{|c|c|c|}
\hline CR $_{\text {eff }}$ & Cw1 & Cw2 \\
\hline 12.4 & 1.48 & 0.869 \\
\hline
\end{tabular}

\section{D Model for Swirl Ratio Estimation}

An extension of the theoretical model described in [20] was used to predict swirl ratio evolution during compression stroke to validate swirl ratio derived from PIV measurements. The model used assumes that the mass of air trapped after IVC is conserved. Additionally, the in-cylinder volume is divided into three volumetric zones as shown in Figure 6. (A green line marks the location of the laser sheet for PIV measurements). Zone 1 considers the volume over the piston bowl. Zone 2 is the annular volume in contact with the liner wall and zone 3 is the bowl volume.

Angular momentum variation over time can be solved in terms of angular momentum transportation by squish flow, angular momentum transportation by viscous shear and angular momentum loss due to wall friction. This model allows for the prediction of the swirl ratio evolution in the three different volumetric zones. The volumetric discretization of the in-cylinder volume also allows for a better comparison of modeling versus experimental results. Accordingly, swirl ratio evolution in volumetric zone 1 is chosen for comparison since the PIV measurements are made over the piston bowl and within a zone contain inside this virtual boundary.

Figure 7 shows modeling results for swirl ratio variation over time. Solid line represents evolution for the reference case considering the measured squish height. Meanwhile the dashed line has been modeled with a bigger squish height to account for the effect of mechanical deformation around TDC. 


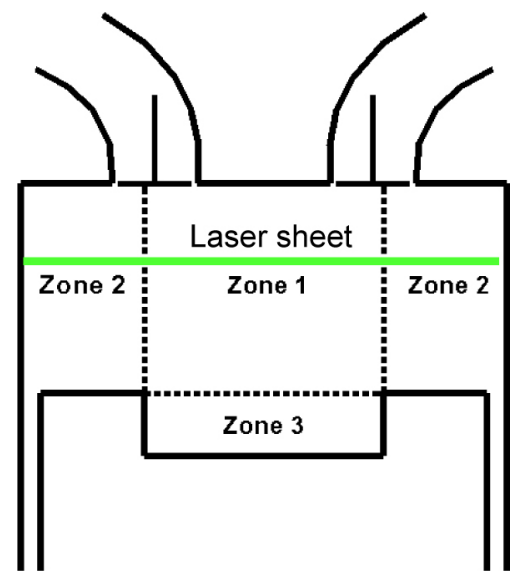

Figure 6. Volumetric zones for swirl ratio calculation.

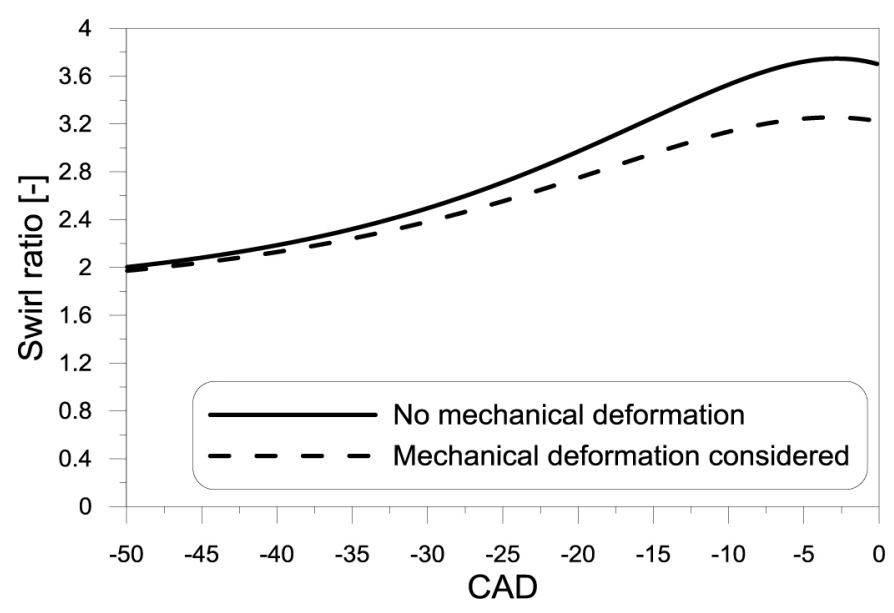

Figure 7. Modeled swirl ratio evolution for volumetric zone over the piston bowl during compression stroke.

\section{METHODOLOGY}

\section{Particle Image Velocimetry System}

A standard PIV (Figure 8) system was used for the measurement of instantaneous two-dimensional velocity fields. One of the system main components is a double-head $15 \mathrm{~Hz} \mathrm{Nd}$ : YAG laser with $135 \mathrm{~mJ} /$ pulse at a $532 \mathrm{~nm}$ wavelength. A set of mirrors are used to drive the laser output $5 \mathrm{~mm}$ circular beam. Then, a Plano-concave cylindrical lens is used to change the laser circular bean into a laser sheet. Finally, a consecutive pair of Plano-convex lenses are used to control laser sheet width and thickness. The measurement section (swirlplane) is located $10 \mathrm{~mm}$ below cylinder head. The laser sheet thickness at this location is approximately $1 \mathrm{~mm}$. The laser sheet goes through the liner optical access and enables the illumination of particles seeded into the intake flow.

After some tests with different kinds of seeding particles and seeding methods, Aluminum Oxide particles were selected. Several tests were made with different aerosols generated with an atomizer using the Laskin nozzle principle (TSI 6-jet atomizer). However, silicon oil, test fluid and other liquids vaporized at the late compression stroke preventing measurements. Regarding tests with solid particles the flow was seeded with a fluidized bed and cyclone. Titanium oxide presented high tendency to agglomerate requiring frequent drying. This behavior made its use impractical in the engine test cell. A better behavior was found with Aluminum Oxide $\left(\mathrm{Al}_{2} \mathrm{O}_{3}\right)$ particles.

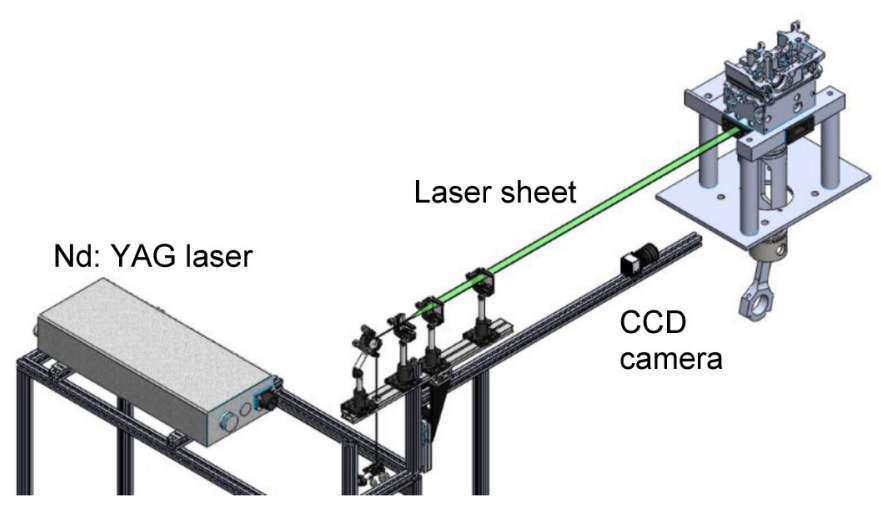

Figure 8. Optical set-up.

Although windows surface wear is known to occur faster $\mathrm{Al}_{2} \mathrm{O}_{3}$ particles do not tend to agglomerate so easily. Consequently, $\mathrm{Al}_{2} \mathrm{O}_{3}$ particles where dispersed with a pulsed fluidized bed device, followed by a specially designed cyclone which blocked out particles with estimated diameters higher than 5 microns. To ensure seeding particles fidelity Stokes number was computed according to the procedure described by Zha et al. []. It was found that Stokes number $\mathrm{S}_{\mathrm{k}}<0.1$ during late compression (PIV measurements in this study are conducted at 37 and 47 CAD bTDC). Based on the Stokes number (Figure 9), seeding particles are expected to follow the in-cylinder flow properly with possible errors below $1 \%[\underline{21}]$.

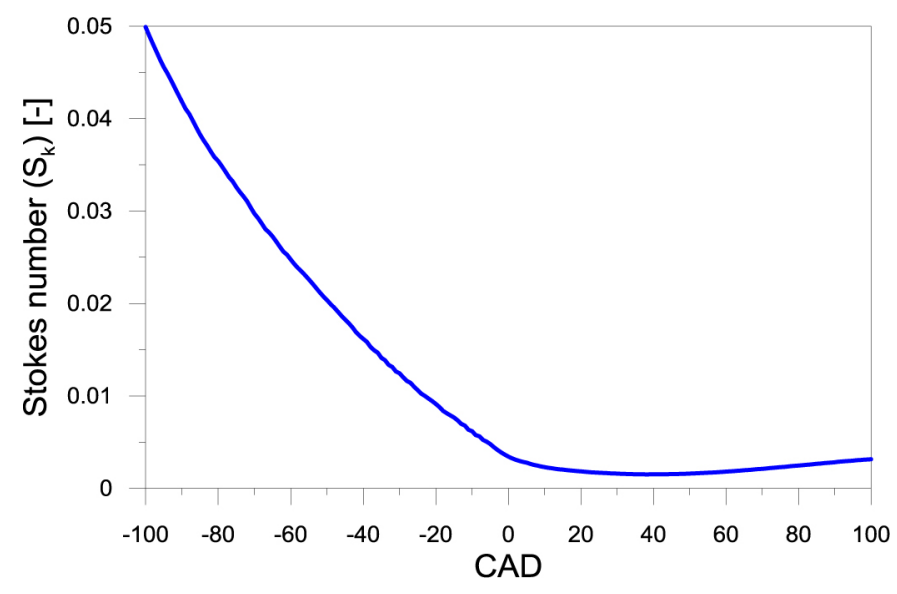

Figure 9. Stokes number used for seeding particles fidelity check.

Light scattered by seeding particles was collected by a 4 megapixels CCD camera in two consecutive frames coincident with two laser shots by means of a synchronization box. Time elapsed between the two laser shots was set to $20 \mu$ s and was kept constant for all test points in the experimental test matrix. This time delay was set to fulfil $\Delta \mathrm{t} \leq \delta / 4 \mathrm{z}$. This condition based on laser sheet thickness $(\delta)$ and an estimated out-of-plane velocity ( $\mathrm{z}$ ) is described in the work by Dannemann et al. (2010) [22]. Based on two frames particle position can be determined using cross-correlation algorithms. Hence, instantaneous two-dimensional velocity fields can be computed based on the displacement of particle groups within a given interrogation area of the image and the time step between frames. The 
magnification of the images taken was around $27 \mathrm{pixel} / \mathrm{mm}$. A cross-correlation approach was employed with 80x80 pixels interrogation areas (25\% maximum particle displacement) with a $50 \%$ overlap. This strategy lead to a velocity field with vectors placed every 40 pixels, i.e. $1.5 \mathrm{~mm}$.

\section{Image Processing}

\section{Calculation of the Flow Field}

In order to have a good description of the velocity field, 100 cycles were measured for each test case and then validated to avoid erroneous vectors. Validation was performed in two stages: first, a Signal to Noise Ratio (SNR) with a 1.3 threshold was used. This filter ensures that only vectors with a peak correlation coefficient higher than 1.3 times the second peak (noise peak) in the correlation coefficient map are included in the velocity field. In a second stage, all the vectors were checked to be within a range of 3 times the standard deviation of the velocity field. Then, any vector three times higher or lower than the median of its 8-neighbours is also refused. In both cases, the rejected vector is replaced by one equal to the mean of its 8-neighbours. Ensemble-averaged velocity fields (see Figure 10) were computed taking into account instantaneous velocity fields with more than $90 \%$ valid velocity vectors (vectors that passed the aforementioned validity check). Out of the 100 measured cycles at least 60 were included in the computation of the ensemble-averaged velocity field. To avoid erroneous correlations due to reflections near the walls, a mask was imposed, so that velocity vectors are obtained for all the cases in a circular region with a diameter of $37 \mathrm{~mm}$, centered in the cylinder axis.

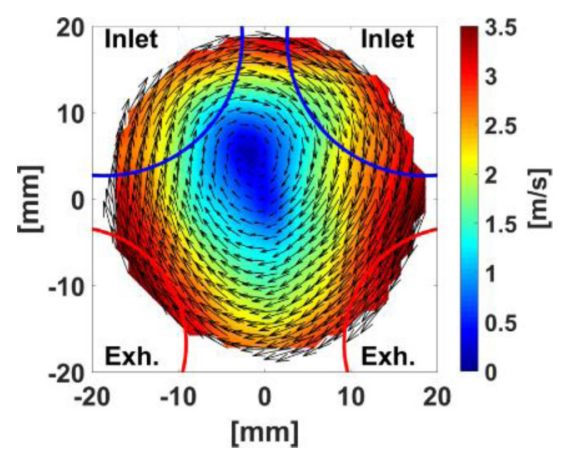

Figure 10. Ensemble-averaged velocity field measured by PIV. Motored case at $47 \mathrm{CAD}$ bTDC.

\section{Calculation of Swirl Ratio}

For a given crank-angle position, swirl ratio $(S R)$ is estimated by dividing the mean angular velocity of the in-cylinder flow and the crankshaft angular velocity $\left(\omega_{\text {eng }}\right)$ according to $(2)$. This expression has been described in []․

$$
S R=\frac{\sum_{i=1}^{N} \omega_{i}}{\omega_{e n g} N}
$$

In-cylinder flow angular velocity is calculated from the ensemble average velocity field (Figure 11), as the tangential component of velocity divided by the distance relative to cylinder axis following expression (3).

$$
\omega_{i}=\frac{\overrightarrow{V_{l}} \cdot \overrightarrow{e_{\perp}}}{\left|\overrightarrow{r_{l}}\right|}
$$

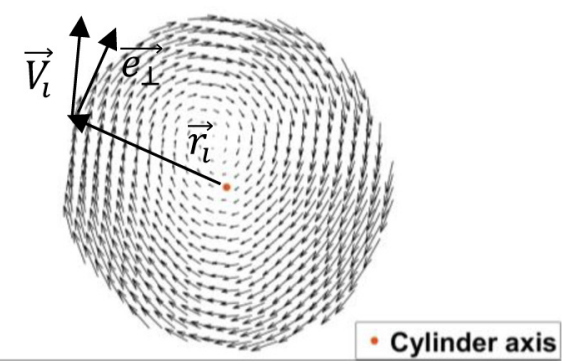

Figure 11. Coordinate system for swirl ratio calculation. Ensemble-averaged velocity motored case at $47 \mathrm{CAD}$ bTDC.

\section{Calculation of Turbulent Kinetic Energy (TKE)}

The computation of the Turbulent Kinetic Energy (TKE) field is made based on the differences between the ensemble-averaged velocity field and the instantaneous fields as expressed in (4).

$$
T K E=\frac{1}{2} \frac{1}{N} \sum_{j=1}^{N}\left(\left(u_{j}-\bar{u}\right)^{2}+\left(v_{j}-\bar{v}\right)^{2}\right)
$$

The ensemble-averaged " $u$ " component of velocity (and analogously for " $v$ " component) is calculated following $(5)$ where $j$ is the number of measured cycles.

$$
\bar{u}=\frac{1}{N} \sum_{j=1}^{N} u_{j}
$$

\section{Experimental Heat Transfer Coefficient Calculation}

It is a common practice to estimate heat transfer coefficients by means of semi-empirical correlations. As described before, CALMEC uses the correlation proposed by Woschni [18]. This correlation can be used to estimate the heat transfer coefficient following the expression (1). Nonetheless, heat transfer coefficient can be calculated with a different approach taking into account local velocities measured by PIV. For that purpose, equation (1) can be rewritten into equation (6) replacing the term considering Woschni coefficients for the local velocity term $\mathrm{w}$. In this expression the value of constant $C$ remains unchanged at $0.012, D$ is the cylinder diameter, $p$ is the measured instant pressure and $T$ is the instant gas temperature estimated by the ideal gas law.

$$
h=C D^{-0.2} p^{0.8} T^{-0.53} w^{0.8}
$$


The local velocity $w$ in $\underline{(6)}$ can be calculated according to $\underline{(7)}$ as described in [23]. This term is a characteristic velocity mainly dependent on the velocity components parallel to the cylinder walls surface and the mean TKE.

$$
w=\sqrt{V_{\text {tang }}^{2}+V_{\text {axial }}^{2}+2 k}
$$

The mean tangential velocity $\left(V_{\text {tang }}\right)$ can be calculated as the sum of the tangential component of all vectors in the measured velocity field divided by the number of observations following (8).

$$
V_{\text {tang }}=\frac{\sum_{i=1}^{N} \vec{V}_{l} \cdot \overrightarrow{e_{\perp}}}{N}
$$

Regarding axial component of velocity it has to be estimated since no PIV measurements are available in vertical sections. The estimation is based on the instant mean piston speed $\left(c_{m}\right)$ and the axial position (with reference to the cylinder head) of the measurement plane $(y)$ and the piston head $\left(y_{\text {piston }}\right)$ according to $\underline{(9)}$.

$$
V_{\text {axial }}=\frac{y}{y_{\text {piston }}} c_{m}
$$

Finally, the variable $k$ is the average TKE in the measured velocity field calculated using (10).

$$
k=\frac{\sum_{i=1}^{N} T K E_{i}}{N}
$$

A comparison of heat transfer calculation approaches is shown in Figure 12. Heat transfer coefficient calculated using the Woschni-like model used in CALMEC is compared with the approach based on experimentally measured velocities. Heat transfer coefficient has been calculated at two crank-angles at which local velocities has been measured by PIV. Engine was motored at a constant velocity of 900 $\mathrm{rpm}$ and intake pressure was set to 2.8 bar.

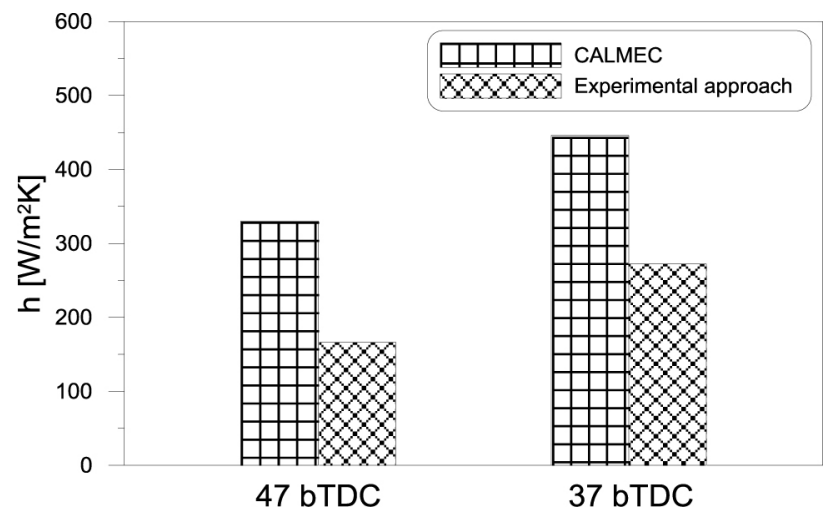

Figure 12. Heat transfer coefficient at 47 and 37 CAD bTDC. Reference cases without fuel injection.
According to Figure 12, it is possible to state that the Woschni-like model used in CALMEC over predicts the heat transfer coefficient when compared to the values estimated with PIV measurements. It is important to remark that CALMEC uses CFD modeled velocities to estimate heat transfer coefficient using expression (1). Therefore, disagreement between CFD modeled velocities and measured velocities is the reason behind differences in heat transfer results. Another source of differences is that heat transfer coefficient calculated in CALMEC is a global parameter. On the other hand, the experimental approach only considers a 2D section in the cylinder. In addition, along this research this coefficient will be used in relative terms. Thus, it is acceptable in spite of differences.

\section{Operating Conditions and Test Matrix}

Engine operating condition were kept constant for all cases in the test matrix. At $900 \mathrm{rpm}$ (optimum frequency for laser-camera synchronization) and 2.8 bar intake pressure window fouling is minimized.

Table 4. Engine operating conditions.

\begin{tabular}{|c|c|}
\hline Engine speed $[\mathrm{rpm}]$ & 900 \\
\hline Intake pressure $[\mathrm{bar}]$ & 2.8 \\
\hline Intake temperature $\left[{ }^{\circ} \mathrm{C}\right]$ & 29.4 \\
\hline $\mathrm{XO}_{2}$ & 0 \\
\hline Swirl valve throttling & Fully open \\
\hline
\end{tabular}

Test matrix is based on a single event advanced pilot injection. Two EoI were tested, i.e. 50 and 40 CAD bTDC. Images were recorded 3 $\mathrm{CAD}$ aEoI, i.e. 47 and $37 \mathrm{CAD}$. Injection pressure was varied from 400 bar up to 1000 bar. Meanwhile, energizing time sweeps were made ranging from 250 to $600 \mu$ s depending on the injection pressure. Depending on the energizing time the start of energizing was variated to maintain fixed the EoI. Momentum flux was increased (by increasing injection pressure or ET) to evaluate its impact on the in-cylinder flow motion.

Table 5. Experimental test matrix.

\begin{tabular}{|c|c|c|c|}
\hline \multicolumn{2}{|c|}{ EoI [CAD] } & Injection pressure [bar] & Injector ET [ $\mu \mathrm{s}]$ \\
\hline \multirow{2}{*}{-50} & \multirow{3}{*}{-40} & 400 & $250 ; 350 ; 500 ; 600$ \\
\cline { 3 - 4 } & & 600 & $250 ; 350 ; 500$ \\
\cline { 3 - 4 } & & 800 & \multirow{2}{*}{350} \\
\cline { 3 - 4 } & & 1000 & \\
\hline
\end{tabular}


For reference purposes, PIV measurements without fuel injection were made for each condition in the test matrix. With this procedure, the evaluation of fuel injection effect on in-cylinder flow pattern in more reliable since the comparison is made with a reference case measured in the same condition.

\section{RESULTS AND DISCUSSIONS}

\section{Effect of Energizing Time}

In order to study the influence of ET on in-cylinder flow field the injection pressure was kept constant at $400 \mathrm{bar}$. This injection pressure enables the broadest ET sweep since window fouling is reduced under this operation condition. Upper part of Figure 14 shows the ensemble-averaged velocity field (left) and spatial TKE distribution (right) for the reference case without fuel injection. Consequently, the figure shows the evolution of the flow field for different ET. Blue and red circles mark the location of the inlet and exhaust valves,

respectively. In addition, dashed white lines are plotted along sprays direction. As ET increases there is a tendency of deceleration of the in-cylinder flow. In a similar way TKE not only tends to decrease but also to be more homogenously distributed.

Figure 13 shows the position of the fuel sprays relative to the laser sheet and piston position at PIV timing 47 CAD bTDC.

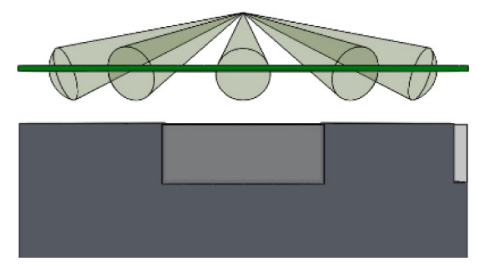

Figure 13. Fuel sprays position relative to laser sheet and piston head at 47 CAD bTDC.

Meanwhile, Figure 15 summarizes the effect of increasing ET on the in-cylinder flow field. Dashed lines represent swirl ratio reference values. The dash-only line represents swirl ratio level derived from measured PIV velocities for a case without fuel injection. The dash-dot line is drawn at the swirl ratio level predicted by the previously described theoretical model. Experimentally derived value for swirl ratio shows a good agreement with the theoretical value in spite of being a 1D model. In this case, the model is over predicting experimental results. Regarding cases where fuel is injected, it can be seen that swirl ratio decreases along with higher ET. This behavior shows that fuel injection influences the tangential component of velocity decelerating the in-cylinder flow.

The decrease in swirl ratio due to spray-swirl interaction leads to a decrease in heat transfer coefficient as shown in Figure 16. This behavior is expected since a lower swirl ratio is a consequence of lower tangential velocities inside the cylinder. Thus, it is possible to state that an increase of momentum flux due to the injection of a bigger amount of fuel leads to a higher homogeneity in the in-cylinder flow with lower heat transfer when early pilot injections are proposed.

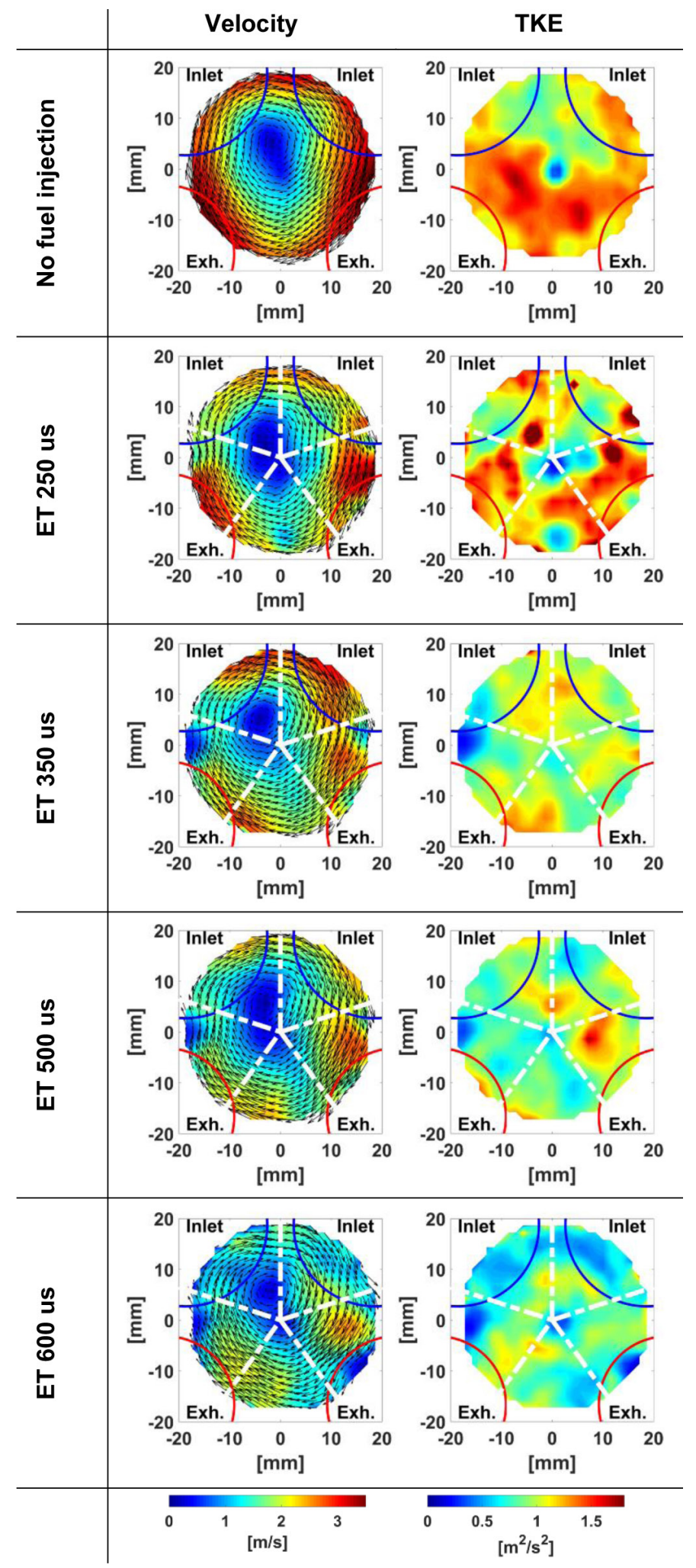

Figure 14. ET influence on flow field at 47 CAD bTDC with 400 bar injection pressure. For all cases EoI is 50 CAD bTDC. Dashed lines are plotted along sprays direction. 


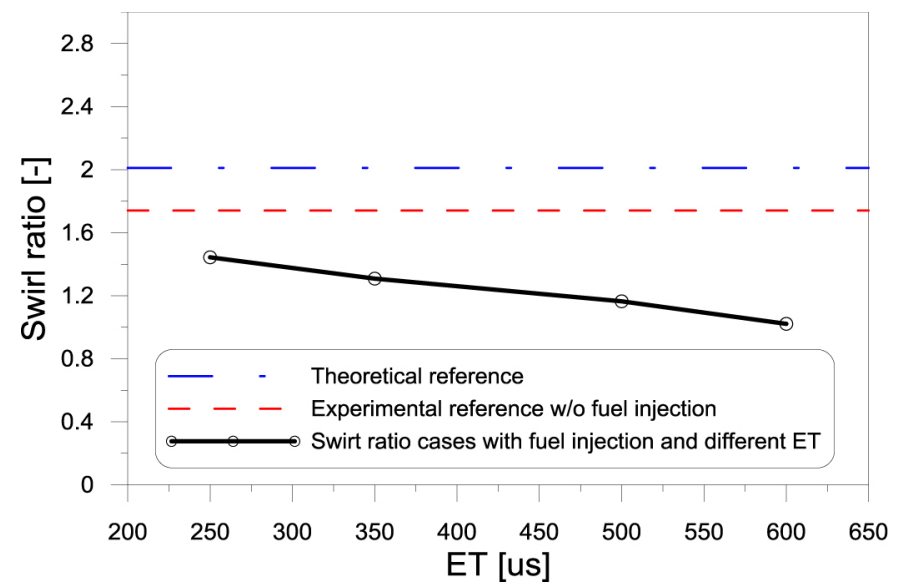

Figure 15. ET influence on swirl ratio at $47 \mathrm{CAD}$ bTDC with 400 bar injection pressure.

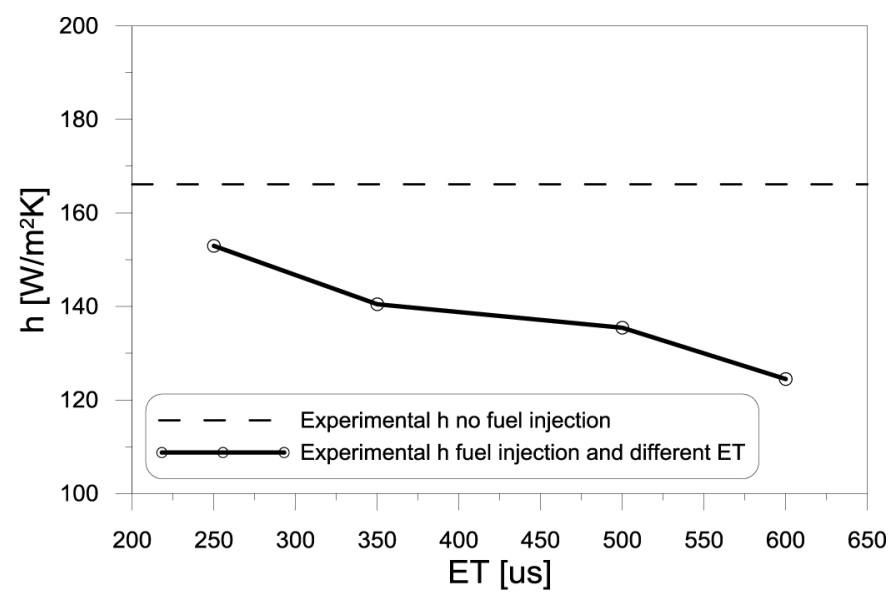

Figure 16. ET effect on heat transfer coefficient at 47 CAD bTDC with 400 bar injection pressure.

\section{Effect of Injection Pressure}

Regarding the effect of fuel injection pressure on in-cylinder flow, Figure 18 shows velocity and TKE maps measured at 37 CAD bTDC. As a reference, the upper part of the figure includes reference maps measured without fuel injection. For the cases considering fuel injection, ET was kept constant at $350 \mu$ s. Fuel injection pressure was swept from 400 bar up to 1000 bar. Higher injection pressures have a tendency to decelerate the velocity field. As for TKE, the area around cylinder axis does not seem to differ much from the reference case without fuel injection. On the contrary, farther away from the cylinder axis there are areas with higher TKE levels compared with the reference case evidencing the increase in turbulence levels associated with higher injection pressures. This trend can be observed in cases with fuel injection pressure ranging from 400 bar to 800 bar. Throw, some discrepancies has been observed for the case with injection pressure 1000 bar. Moreover, Figure 17 shows fuel sprays as well as laser sheet and piston head position at $37 \mathrm{CAD}$ bTDC.

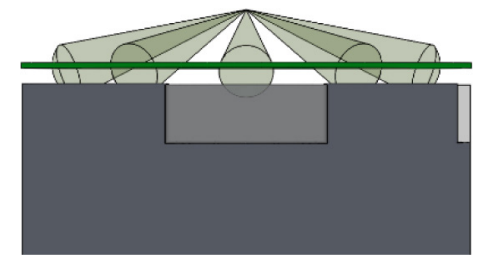

Figure 17. Fuel sprays position relative to laser sheet and piston head at 37 CAD bTDC

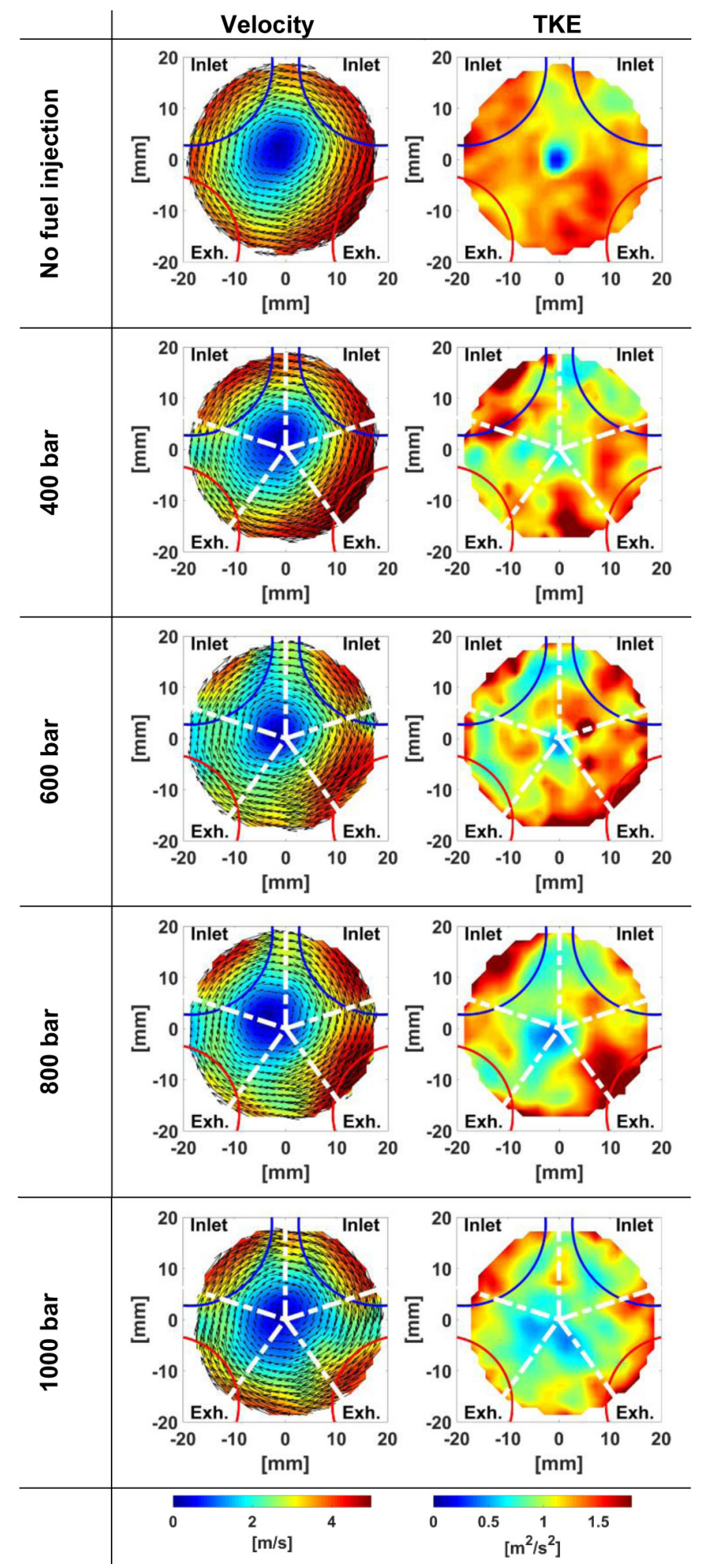

Figure 18. Injection pressure influence flow field at $37 \mathrm{CAD}$ bTDC with $350 \mu$ s ET. For all cases EoI is $40 \mathrm{CAD}$ bTDC. Dashed lines are plotted along sprays direction. 
To better understand fuel injection pressure effect on in-cylinder flow, swirl ratio evolution for different injection pressures is plotted in Figure 19. As in the previous case, dashed line represents swirl ratio levels in reference condition without fuel injection. Meanwhile, dashed-dotted line is showing the swirl ratio level predicted by the theoretical model. In this case, theoretical model is under predicting experiential results. Nonetheless, both values are close which evidence a good consistency level between experiments and calculations. In addition, swirl ratio for cases with fuel injection is also presented. All of them follow a decreasing trend when injection pressure is increased, showing an analogous behavior as in the case of increasing ET.

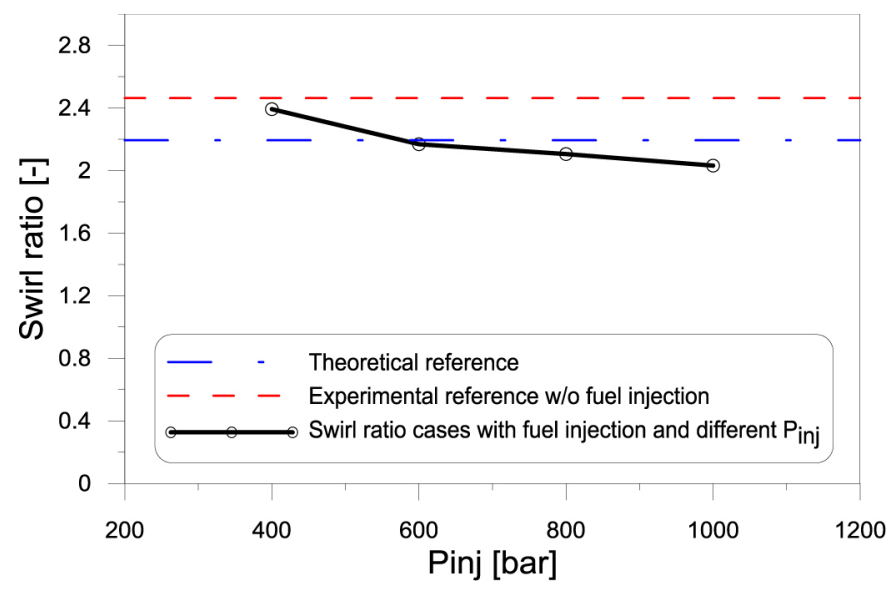

Figure 19. Injection pressure influence on swirl ratio at 37 CAD bTDC with $350 \mu \mathrm{s}$ ET.

In a similar way as with the sweep of ET, the increase of momentum flux due to higher injection pressure and hence higher injection velocities tends to deaccelerate the in-cylinder flow in the swirlplane. This flow deceleration comes with a drop of swirl ratio and consequently with a drop of the heat transfer coefficient as shown in Figure 20.

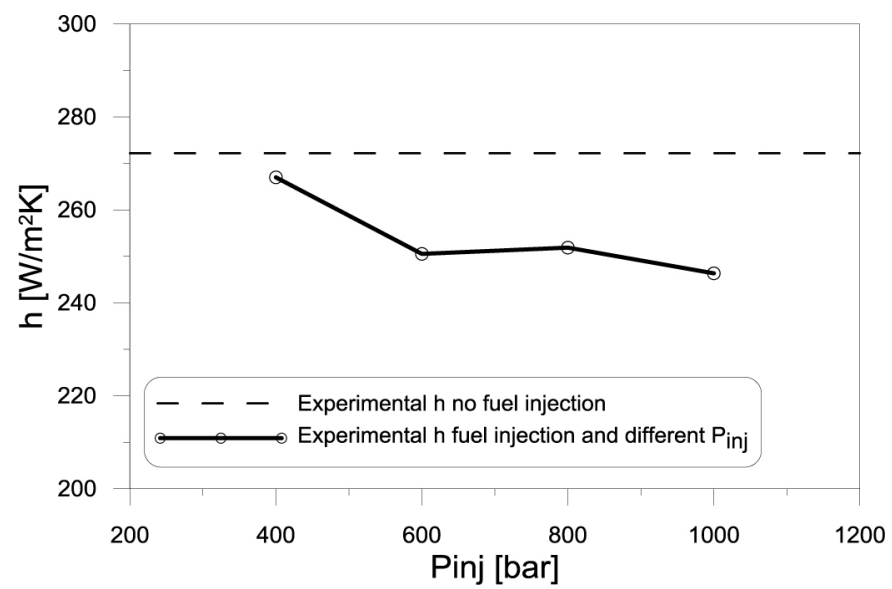

Figure 20. Injection pressure effect on heat transfer coefficient at $37 \mathrm{CAD}$ bTDC with $350 \mu$ sT.

\section{Effect of End of Injection Timing}

To study injection timing effect of the swirl-spray interaction, injection pressure was kept constant at 600 bar while EoI was set to 40 bTDC and 50 bTDC. Measurements were made 3 CAD aEoI. Figure 21 and Figure 22 shows velocity and TKE maps for the two different EoI and for two ET values, namely 250 and $500 \mu \mathrm{s}$. As expected, higher velocities are reached closer to TDC. Regarding TKE, cases measured at $47 \mathrm{bTDC}$ seem to have a more homogenous distribution compared to cases closer to TDC which show zones with high TKE levels especially away from the cylinder axis.

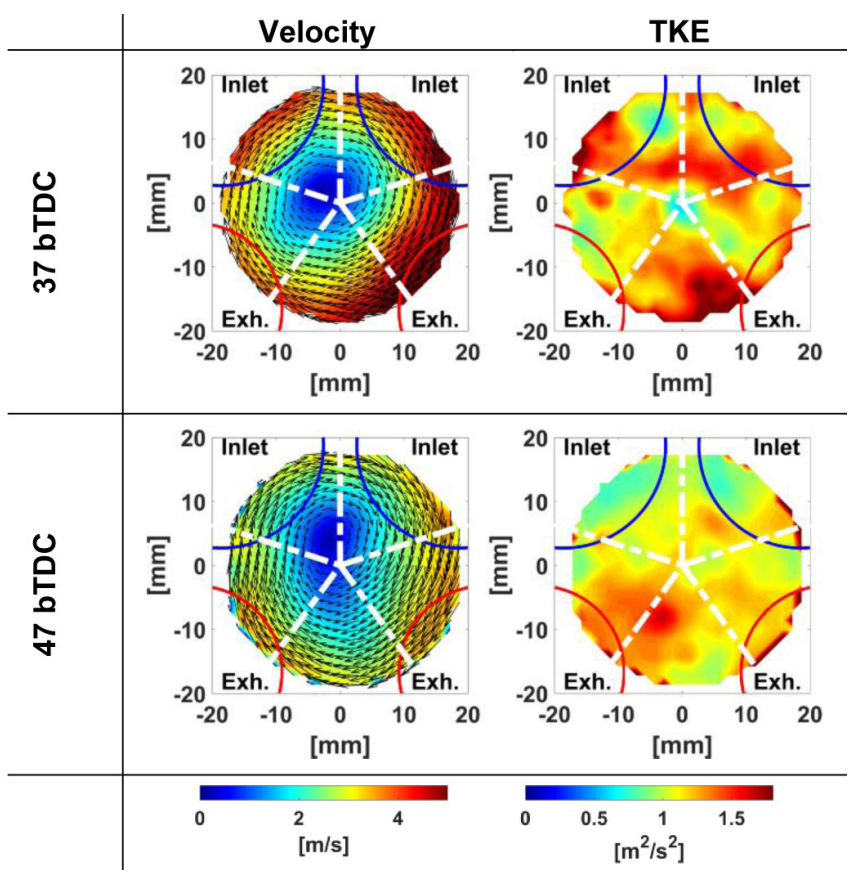

Figure 21. Comparison of injection timing effect on in-cylinder flow field. Fuel injected at 600 bar and 250 us energizing time. Dashed lines are plotted along sprays direction

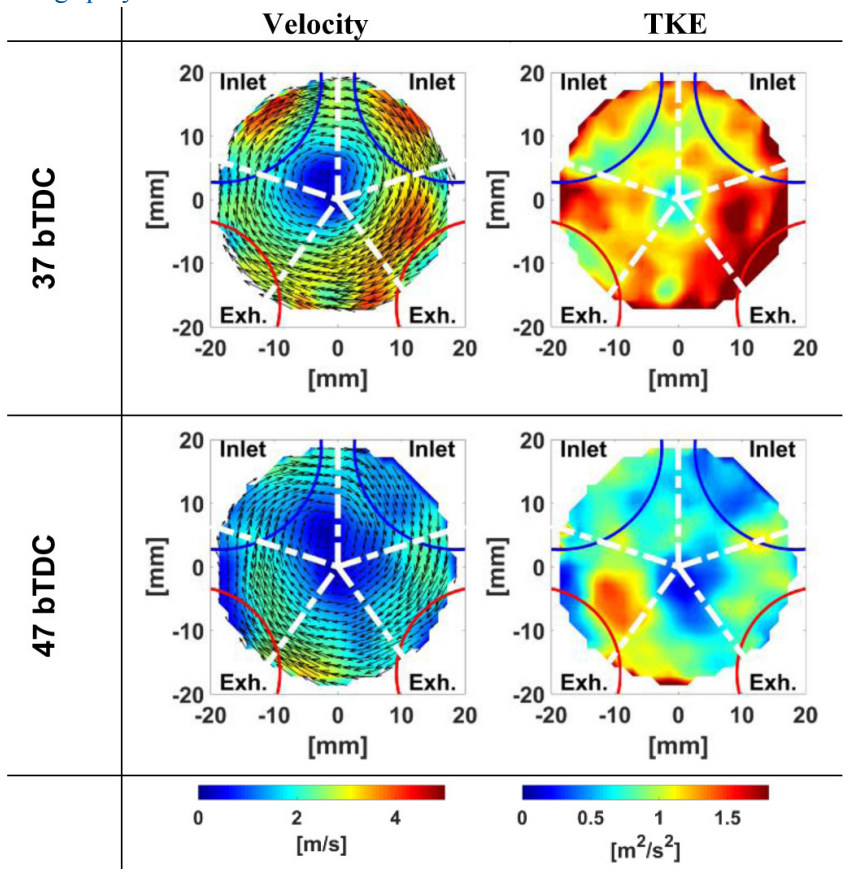

Figure 22. Comparison of injection timing effect on in-cylinder flow field. Fuel injected at 600 bar and 500 us energizing time. Dashed lines are plotted along sprays direction 
To summarize results regarding EoI variation and its effect on in-cylinder flow, Figure 23 shows swirl ratio evolution for different ET and crank-angles. Differences in swirl ratio levels between measurements made at $47 \mathrm{bTDC}$ and $37 \mathrm{bTDC}$ are expected since it has been shown that swirl ratio increases towards TDC. In spite of that, the trend to decrease swirl ratio by increasing ET remains for both cases.

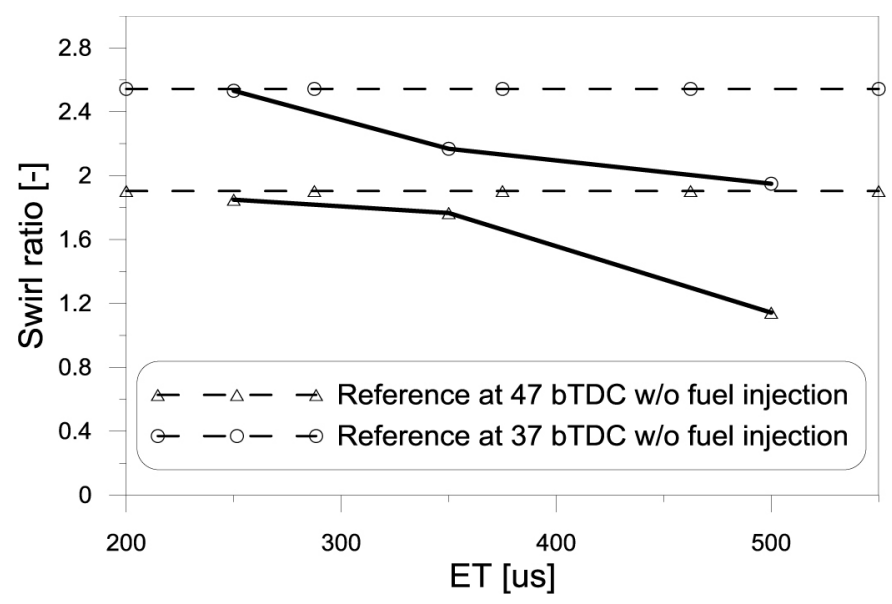

Figure 23. Comparison of injection timing effect on swirl ratio. For all cases fuel is injected at 600 bar.

\section{SUMMARY/CONCLUSIONS}

This paper has presented the interaction of fuel spray and in-cylinder flow field. The study is based on the analysis of the in-cylinder velocity field measured by PIV. A light-duty optical Diesel engine was used for the experimental test. Fuel was injected under nonreacting PCCI conditions. ET and injection pressure were swept. Main conclusions are:

- A dedicated methodology has been developed to wellcharacterize optical engines using elongated Bowditch pistons.

- An experimental approach to calculate heat transfer coefficient has been presented and validated.

- Concerning the swirl-spray interaction, the following observation have been made:

- For a constant injection pressure, the increase in ET decelerates in-cylinder flow hence decreasing swirl ratio. Furthermore, TKE shows a similar trend with lower levels and a more homogenous distribution. The decrease in swirl ratio and TKE leads to a decrease in the heat transfer coefficient.

- Regarding an increase in injection pressure at constant ET, in-cylinder flow tends to decelerate showing again a decrease in swirl ratio. Nonetheless, unlike the case with ET swept, TKE maps shows zones with higher TKE levels compared to the reference case with fuel injection. Global tendency for heat transfer coefficient is to decrease with the increase in injection pressure.

- At a constant injection pressure, ET was swept for two different EoI. It was found that swirl ratio decreases with fuel injection regardless of crank-angle.

\section{REFERENCES}

1. Torregrosa, A.J., Broatch, A., García, A., and Mónico, L.F., "Sensitivity of combustion noise and $\mathrm{NOx}$ and soot emissions to pilot injection in PCCI diesel engines", Applied Energy 104:149-157, 2013, doi:10.1016/j.apenergy.2012.11.040.

2. Kiplimo, R., Tomita, E., Kawahara, N., and Yokobe, S., "Effects of spray impingement, injection parameters, and EGR on the combustion and emission characteristics of a PCCI diesel engine", Applied Thermal Engineering 37:165-175, 2012, doi:10.1016/j. applthermaleng.2011.11.011.

3. Kanda, T., Hakozaki, T., Uchimoto, T., Hatano, J. et al., "PCCI Operation with Early Injection of Conventional Diesel Fuel," SAE Technical Paper 2005-01-0378, 2005, doi:10.4271/2005-01-0378.

4. Neely, G., Sasaki, S., and Leet, J., "Experimental Investigation of PCCIDI Combustion on Emissions in a Light-Duty Diesel Engine," SAE Technical Paper 2004-01-0121, 2004, doi:10.4271/2004-01-0121.

5. Zha, K., Busch, S., Miles, P., Wijeyakulasuriya, S. et al., "Characterization of Flow Asymmetry During the Compression Stroke Using Swirl-Plane PIV in a Light-Duty Optical Diesel Engine with the Re-entrant Piston Bowl Geometry," SAE Int. J. Engines 8(4):1837-1855, 2015, doi:10.4271/2015-01-1699.

6. Payri, F., Desantes, J.M., and Pastor, J.V., "LDV measurements of the flow inside the combustion chamber of a 4-valve D.I. Diesel engine with axisymmetric piston-bowls", Experiments in Fluids 22(2):118-128, 1996, doi: $10.1007 / \mathrm{s} 003480050029$.

7. Zegers, R.P.C., Luijten, C.C.M., Dam, N.J., and Goey, L.P.H. de, "Preand post-injection flow characterization in a heavy-duty diesel engine using high-speed PIV", Experiments in Fluids 53(3):731-746, 2012, doi: $10.1007 / \mathrm{s} 00348-012-1323-3$.

8. Valentino, G., Allocca, L., and Marchitto, L., "PIV Investigation of High Swirl Flow on Spray Structure and its Effect on Emissions in a Diesel-Like Environment," SAE Technical Paper 2011-01-1286, 2011, doi:10.4271/2011-01-1286.

9. Dembinski, H.W., "The effects of injection pressure and swirl on incylinder flow pattern and combustion in a compression-ignition engine", International Journal of Engine Research 15(4):444-459, 2013, doi: 10.1177/1468087413491262.

10. Dembinski, H. and Angstrom, H., "Swirl and Injection Pressure Impact on After-Oxidation in Diesel Combustion, Examined with Simultaneous Combustion Image Velocimetry and Two Colour Optical Method," SAE Technical Paper 2013-01-0913, 2013, doi:10.4271/2013-01-0913.

11. Tanov, S., Wang, Z., Wang, H., Richter, M. et al., "Effects of Injection Strategies on Fluid Flow and Turbulence in Partially Premixed Combustion (PPC) in a Light Duty Engine," SAE Technical Paper 2015 24-2455, 2015, doi:10.4271/2015-24-2455.

12. Bowditch, F., "A New Tool for Combustion Research A Quartz Piston Engine," SAE Technical Paper 610002, 1961, doi:10.4271/610002.

13. Benajes, J., Olmeda, P., Martín, J. and Carreño, R., "A new methodology for uncertainties characterization in combustion diagnosis and thermodynamic modelling", Applied Thermal Engineering 71:389-399, 2014, doi:10.1016/j.applthermaleng.2014.07.010.

14. Payri F., Olmeda P., Martín J., García, Antonio. “A complete $0 \mathrm{D}$ thermodynamic predictive model for direct injection diesel engines", Applied Energy (88) (2011) 4632-4641. doi:10.1016/i. apenergy.2011.06.005.

15. Payri, F., Galindo, J., Martín, J., and Arnau, F., "A Simple Model for Predicting the Trapped Mass in a DI Diesel Engine," SAE Technical Paper 2007-01-0494, 2007, doi:10.4271/2007-01-0494.

16. Lapuerta M, Armas O, Hernández JJ. "Diagnosis of DI Diesel combustion from in- cylinder pressure signal by estimation of mean thermodynamic properties of the gas". Appl Thermal Eng 1999; 19(5):513-29. http://dx.doi.org/10.1016/S1359-4311(98)00075-1.

17. Payri F, Molina S, Martín J, Armas O. "Influence of measurement errors and estimated parameters on combustion diagnosis". Appl Thermal Eng 2006; 26(2-3):226-3, http://dx.doi.o10.1016/j. applthermaleng.2005.05.006.

18. Payri, F., Margot, X., Gil, A., and Martin, J., "Computational Study of Heat Transfer to the Walls of a DI Diesel Engine," SAE Technical Paper 2005-01-0210, 2005, doi:10.4271/2005-01-0210.

19. Aronsson, U., Solaka, H., Lequien, G., Andersson, O. et al., "Analysis of Errors in Heat Release Calculations Due to Distortion of the In-Cylinder Volume Trace from Mechanical Deformation in Optical Diesel Engines," SAE Int. J. Engines 5(4):1561-1570, 2012, doi:10.4271/2012-01-1604.

20. Murakami, A., Arai, M., and Hiroyasu, H., "Swirl Measurements and Modeling in Direct Injection Diesel Engines," SAE Technical Paper $\underline{880385}, 1988$, doi: $10.4271 / 880385$. 
21. Tropea, C., Yarin, A. L. and Foss, J. F., "Springer Handbook of Experimental Fluid Mechanics", (Berlin Heidelberg, Springer Verlag, 2007), p289, ISBN-13: 978-3-540-25141-5.

22. Dannemann, J., Pielhop, K., Klaas, M., and Schröder, W., "Cycle resolved multi-planar flow measurements in a four-valve combustion engine," Experiments in Fluids 50(4):961-976, 2010, doi: 10.1007/ s00348-010-0963-4.

23. Schubert, C., Wimmer, A., and Chmela, F., "Advanced Heat Transfer Model for CI Engines," SAE Technical Paper 2005-01-0695, 2005, doi:10.4271/2005-01-0695.

\section{CONTACT INFORMATION}

Dr. Antonio García

CMT-Motores Térmicos, Universitat Politècnica de València

Camino de Vera s/n, 46022 Valencia (Spain)

angarma8@mot.upv.es

www.cmt.upv.es

\section{ACKNOWLEDGMENTS}

The support of the Spanish Ministry of Economy and Competitiveness (TRA2014-58870-R,) is greatly acknowledged through HiReCo project.

\section{DEFINITIONS/ABBREVIATIONS}

0D - Zero-dimensional

1D - One-dimentional

aEoI - After end of injection

$\mathbf{A l}_{2} \mathbf{O}_{3}$ - Aluminum oxide

bTDC - Before top dead center
CAD - Crank-angle degree

CCD - Charge-coupled device

CFD - Computer fluid dynamics

CI - Compression ignition

CIV - Combustion image velocimetry

$\mathbf{C R}_{\text {eff }}$ - Effective compression ratio

Cw1 - Woschni coefficient 1

Cw2 - Woschni coefficient 2

EoI - End of injection

ET - Energizing time

EVO - Exhaust valve opening

h - Heat transfer coefficient

HC - Hydrocarbons

IVC - Intake valve closing

Nd: YAG - Neodymium-doped yttrium aluminium garnet

NOx - Nitrogen oxide

PCCI - Premix charge compression ignition

PID - Proportional-integral-derivative

PIV - Particle image velocimetry

PM - Particulate matter

RoHR - Rate of heat release

rpm - Revolution per minute

TDC - Top dead center

TKE - Turbulent kinetic energy

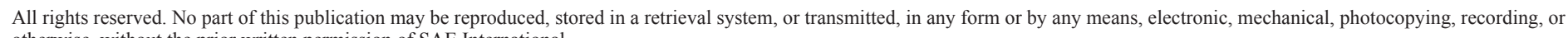
otherwise, without the prior written permission of SAE International. 